\title{
The Impact of Air or Nitrogen Non-Thermal Plasma on Variations of Natural Bioactive Compounds in Djulis (Chenopodium formosanum Koidz.) Seed and the Potential Effects for Human Health
}

\author{
Bing-Jyh Lu ${ }^{1}\left(\mathbb{D}\right.$, Tzu-Che Lin ${ }^{2, \dagger}$, How-Ran Chao ${ }^{3,4,5,6, *,+} \mathbb{D}$, Cheng-Hsian Tsai ${ }^{1,+} \mathbb{D}$, Jian-He Lu ${ }^{6}$, \\ Ming-Hsien Tsai ${ }^{7}$, Ching-Tzu Chang ${ }^{4}$, Hao Hsieh ${ }^{3}$, I-Cheng Lu ${ }^{3}$, Rachelle D. Arcega ${ }^{8}$, Wei-Hsiang Chang ${ }^{8}$, \\ Hsiu-Ling Chen ${ }^{8}\left(\mathbb{D}\right.$, Wan Nurdiyana Wan Mansor $9,10\left(\mathbb{D}\right.$ and Ying-Chieh Lee ${ }^{11}(\mathbb{D})$
}

check for
updates

Citation: Lu, B.-J.; Lin, T.-C.; Chao, H.-R.; Tsai, C.-H.; Lu, J.-H.; Tsai, M.-H.; Chang, C.-T.; Hsieh, H.; Lu, I.-C.; Arcega, R.D.; et al. The Impact of Air or Nitrogen Non-Thermal Plasma on Variations of Natural Bioactive Compounds in Djulis (Chenopodium formosanum Koidz.) Seed and the Potential Effects for Human Health. Atmosphere 2021, 12, 1375. https://doi.org/10.3390/ atmos12111375

Academic Editors: Marco Dettori, Gea Oliveri Conti, Marco Gola and Neveen Hamza

Received: 20 September 2021 Accepted: 14 October 2021 Published: 21 October 2021

Publisher's Note: MDPI stays neutral with regard to jurisdictional claims in published maps and institutional affiliations.

Copyright: (c) 2021 by the authors. Licensee MDPI, Basel, Switzerland. This article is an open access article distributed under the terms and conditions of the Creative Commons Attribution (CC BY) license (https:/ / creativecommons.org/licenses/by/ $4.0 /)$.
1 Department of Chemical and Materials Engineering, College of Engineering, National Kaohsiung University of Science and Technology, Sanmin District, Kaohsiung City 807, Taiwan; 1101411103@nkust.edu.tw (B.-J.L.); chtsai@kuas.edu.tw (C.-H.T.)

2 Department of Plant Industry, College of Agriculture, National Pingtung University of Science and Technology, Pingtung County 912, Taiwan; tclin@mail.npust.edu.tw

3 Department of Environmental Science and Engineering, College of Engineering, National Pingtung University of Science and Technology, Pingtung County 912, Taiwan; m10831018@mail.npust.edu.tw (H.H.); p10831003@mail.npust.edu.tw (I.-C.L.)

4 Institute of Food Safety Management, College of Agriculture, National Pingtung University of Science and Technology, Pingtung County 912, Taiwan; m10828006@mail.npust.edu.tw

5 General Research Service Center, National Pingtung University Science and Technology, Pingtung County 912, Taiwan

6 School of Dentistry, College of Dental Medicine, Kaohsiung Medical University, Kaohsiung City 807, Taiwan; toddherpuma@mail.npust.edu.tw

7 Department of Child Care, College of Humanities and Social Sciences, National Pingtung University of Science and Technology, Pingtung County 912, Taiwan; alantsai@mail.npust.edu.tw

8 Department of Food Safety/Hygiene and Risk Management, College of Medicine, National Cheng Kung University, Tainan City 701, Taiwan; sc6087028@mail.ncku.edu.tw (R.D.A.); whchang@mail.ncku.edu.tw (W.-H.C.); hsiulinchen@mail.ncku.edu.tw (H.-L.C.)

9 Faculty of Ocean Engineering Technology \& Informatics, Universiti Malaysia Terengganu, Kuala Nerus 21030 , Malaysia; nurdiyana@umt.edu.my

10 Air Quality and Environment Research Group, Universiti Malaysia Terengganu, Kuala Nerus 21300, Malaysia

11 Institute of Material Engineering, College of Engineering, National Pingtung University of Science and Technology, Pingtung County 912, Taiwan; YCLee@mail.npust.edu.tw

* Correspondence: hrchao@mail.npust.edu.tw; Tel.: +886-8-7703202 (ext. 7517); Fax: +886-8-7740256

+ These authors contributed equally.

Abstract: Non-thermal plasma (NTP) has been widely applied in the food and agricultural industries. It is still unknown whether natural bioactive compounds in seeds are affected by NTP treatment. Our goal was to examine whether the bioactive compounds in djulis (Chenopodium formosanum Koidz.) seed are changed after NTP treatment. The betacyanin, anthocyanin, total phenolic content (TPCs), total flavonoids (TFs), 2,2-diphenyl-1-picrylhydrazyl radical scavenging effects (DPPH), gallic acid, and rutin were compared in NTP-treated seed and an untreated control. Levels of betacyanin, anthocyanin, and TPCs in the seed were found to be significantly increased after the nitrogen $\left(\mathrm{N}_{2}\right)$-NTP treatment compared with the control $(p<0.001)$. Inversely, the air-NTP treatment significantly weakened the performance of these bioactive compounds in the seed as compared to the control. Levels of TFs in both the air- and $\mathrm{N}_{2}$-NTP treated seed were significantly lower than those in the control $(p<0.001)$. After the NTP treatment, DPPH was still at high levels, similar to those in the control. The djulis seed extract had antioxidant and anti-inflammatory effects on THP-1 (human-monocyte-cell line) cells. $\mathrm{N}_{2}$-NTP generated nitrogen reactive species that activated the bioactive compounds in the seed. In contrast, air-NTP produced oxygen and nitrogen reactive species inhibited the expression of these bioactive compounds. 
Keywords: non-thermal plasma (NTP); djulis; seed; reactive oxygen and nitrogen species; bioactive compounds; antioxidant; THP-1 cells

\section{Introduction}

Non-thermal pressure plasma or non-thermal plasma (NTP) generates plasma ionizing gases that damage biological targets (e.g., cancer cells) without increasing the temperature in the treated regions through the formation of free radicals, photons, positive ions, free electrons, and an electromagnetic field. Cold atmospheric plasma (CAP), which is an NTP device, is a neutral ionized gas consisting of positive charge ions, neutral particles, electrons, and UV radiation at near room temperature. NTP has been widely applied to medical therapy, biomedical materials, and food technology for decades [1-3]. Several reactive oxygen species (ROS) and nitrogen species (RNS) are created in NTP [4]. In food technology, NTP, including CAP, is an innovative technique used to improve the inactivation of pathogens (e.g., Salmonella typhimurium) [5] or spoilage organisms (e.g., Saccharomyces cerevisiae) [3], parasite control [6], seed germination [7,8], and acceleration of seed growth $[8,9]$. Compared with traditional food techniques, NTP may offer several advantages, including that it can be used at room temperature in a dry environment; is a fast, safe treatment; and there are no chemical residues developed under operating conditions. It is an eco-friendly, highly sensitive, economic approach to plant health $[10,11]$.

Treatment with NTP may modify the surface of the seed and notably induce the germination process, make it easy for the seed to take in nutrients and water, and change its affinity to water [12]. NTP can damage the seed envelope, and its reactive species can penetrate the seed coat to disrupt the inner embryo and DNA [12,13]. Plasma techniques have been applied for agricultural purposes, especially for the growth of vegetation, for a decade. The positive impact of NTP treatment on the acceleration of germination and improvement of root, shoot, and young seedling growth has been demonstrated in previous studies [8,9,12-14].

Djulis (Chenopodium formosanum Koidz.), commonly referred to as Taiwanese red quinoa, is a traditional pseudocereal crop that is an endemic species and a local flora in Taiwan. Botanically speaking, djulis belongs to the Amaranthaceae family under the genus Chenopodium and has a close botanical similarity to quinoa (Chenopodium quinoa) [15]. Djulis has been cultivated by the aborigines in southern Taiwan for over a hundred years, and, traditionally, it is used as an ingredient in local winemaking and as a major part of the aboriginal diet [16]. Djulis has been documented to be a rich source of minerals, vitamins, and high-quality proteins and provides all eight essential amino acids $[17,18]$. However, scientific interest in djulis only surfaced after a seminal study revealed that the bioactive compound, betacyanin, present in djulis is responsible not only for the plant's bright red color but also for its strong antioxidant capacities [18]. In addition, other types of antioxidants, including phytosterols, flavonoids, and phenolic acids, have been isolated from djulis $[2,15]$. More recently, in vitro and in vivo studies have shown that the bioactive compounds present in djulis are responsible for its ability to lower low-density-lipoprotein cholesterol levels [19], protect the liver from injury [20,21], ameliorate dermal damage [17], and demonstrate chemopreventive effects against colon cancer [22,23].

This is a preliminary study intended to examine whether levels of natural bioactive compounds, particularly for the chemicals such as polyphenols, betacyanin, anthocyanin, flavonoids, and 2,2-diphenyl-1-picrylhydrazyl (DPPH)radical scavenging effects against oxidative stress and inflammation, in djulis seed are changed after the seed is treated with NTP (air and nitrogen $\left(\mathrm{N}_{2}\right)$ NTP).

\section{Materials and Methods}

\subsection{Chemicals and Reagents}

Chemicals including rutin, quercetin, DPPH, epicatechin, 6-di-tert-butyl-4-methylphenol (BHT), phthaldialdehyde, and 3-mercaptopropionic acid were purchased from Millipore- 
Sigma (Merck KGaA, Burlington, MA, USA). The methanol and ethanol were obtained from JT-Baker (Fisher Scientific, Loughborough, UK). Formic acid, 2-propanol, and acetonitrile were obtained from Honeywell Research Chemicals (Fisher Scientific).

\subsection{Djulis Seeds Treated Using NTP}

The djulis seed was directly harvested from the sustainable agricultural farms at National Pingtung University of Science and Technology (SAF/NPUST) or purchased from a retail store carrying products from SAF/NPUST. The atmospheric-pressure AC plasma system used as the NTP (Non-Thermal Atmospheric Pressure Plasma SAP013RT-300RB) was designed and purchased from Creating Nano Technologies Inc. (Tainan, Taiwan). The SAP013RT-300RB, including a plasma jet (torch) and the plasma input power supply (plasma input power: $600-800 \mathrm{~W}$; plasma frequency: $20-40 \mathrm{kHz}$ ), was equipped with a three-axis automated glue dispensing robot (LI HSI Technology Co., LTD, Taipei, Taiwan) to treat $1 \mathrm{~g}$ (g) of djulis seed in a $60 \mathrm{~mm}$ Petri dish covered with a stainless-steel mesh and clipped onto a platform. Djulis seed from the NPUST retail store was treated with air NTP (air-NTP), and the seed from SAF/NPUST was treated with $\mathrm{N}_{2}$ NTP $\left(\mathrm{N}_{2}-\mathrm{NTP}\right)$. The high-purity working gases $\left(>99.99 \%\right.$ ), including air and $\mathrm{N}_{2}$, were obtained from Air Products and Chemicals, Inc. (Taiwan). The NTP-mediated gaseous ionization and plasma electronics on the seed surface were determined based on the plasma nozzle parameters (A50 (50 mm), A30 $(30 \mathrm{~mm})$, and A10 $(10 \mathrm{~mm}))$, sweep speed, or contact time (100 and $150 \mathrm{~mm} / \mathrm{s})$, input power (600 and $800 \mathrm{~W}$ ), the distance from the seed to the plasma nozzles $(5,10,15 \mathrm{~mm})$, and the working gas (Table 1). The spectrum of the plasma radiation and functional groups of the seed were analyzed using an optical emission spectrometer (OES) (HR 4000CG, Ocean Optics, Orlando, FL, USA) and Fourier-transform infrared spectroscopy (FTIR) (Spectrum One, Perkin Elmer, Waltham, MA, USA), respectively. The morphological properties of the surface of the djulis seed were scanned with a scanning electron microscope (SEM) (S3000N, Hitachi, Tokyo, Japan).

Table 1. Parameters of the NTP-treated djulis seed in this study.

\begin{tabular}{|c|c|c|c|c|c|c|c|c|}
\hline Method & $\begin{array}{c}\text { Plasma Nozzle } \\
\text { A50/A30/A10 }\end{array}$ & $\begin{array}{l}\text { Distance }^{a} \\
5 / / 10 / 15 \mathrm{~mm}\end{array}$ & $\begin{array}{c}\text { Plasma Gas } \\
\text { Air/ } \mathbf{N}_{2}\end{array}$ & $\begin{array}{l}\text { Power Input } \\
0.6 / 0.8 \mathrm{~kW}\end{array}$ & $\begin{array}{c}\text { Sweep } \\
\text { Speed } \\
100 / 150 \mathrm{~mm} / \mathrm{s}\end{array}$ & $\begin{array}{c}\text { Temperature } \\
\mathbf{b}\left({ }^{\circ} \mathrm{C}\right)\end{array}$ & $\begin{array}{c}\text { Torch } \\
\text { Diameter } \\
\text { c }(\mathrm{mm})\end{array}$ & $\begin{array}{l}\text { Treatment } \\
\text { Time (Sec) }\end{array}$ \\
\hline Control & None & None & None & None & None & None & None & None \\
\hline Method A & A50 & 5 & Air $/ N_{2}$ & 0.6 & 100 & 49 & 42 & 1.02 \\
\hline Method B & A50 & 5 & Air $/ N_{2}$ & 0.8 & 100 & 59 & 42 & 1.02 \\
\hline Method C & A50 & 5 & Air $/ N_{2}$ & 0.8 & 150 & 46 & 42 & 0.68 \\
\hline Method D & A50 & 10 & Air $/ N_{2}$ & 0.8 & 100 & 54 & 42 & 1.02 \\
\hline Method E & A30 & 5 & Air $/ N_{2}$ & 0.8 & 100 & 55 & 30 & 0.90 \\
\hline Method F & A30 & 10 & Air $/ N_{2}$ & 0.8 & 100 & 52 & 30 & 0.90 \\
\hline Method G & A30 & 5 & Air $/ N_{2}$ & 0.8 & 150 & 47 & 30 & 0.60 \\
\hline Method H & A30 & 5 & Air $/ N_{2}$ & 0.6 & 100 & 49 & 30 & 0.90 \\
\hline Method I & A10 & 15 & Air $/ N_{2}$ & 0.8 & 100 & 75 & 17 & 0.77 \\
\hline Method J & A10 & 15 & Air $/ N_{2}$ & 0.8 & 150 & 57 & 17 & 0.51 \\
\hline Method K & A10 & 15 & Air $/ N_{2}$ & 0.6 & 100 & 67 & 17 & 0.77 \\
\hline Method L & A10 & 10 & Air $/ N_{2}$ & 0.8 & 100 & 77 & 17 & 0.77 \\
\hline
\end{tabular}

${ }^{a}$ Distance from the seed surface to the plasma nozzle. ${ }^{b}$ Surface temperature on the djulis seed. ${ }^{c}$ Diameter of the NTP torch.

\subsection{Analysis of Natural Bioactive Compounds}

The seed powder was ground regardless of whether or not it was treated with NTP. For this, $0.1 \mathrm{~g}$ of powder was extracted using $10 \mathrm{~mL}$ distilled and deionized (DD) water or ethanol for $24 \mathrm{~h}$ and then centrifuged for $3500 \mathrm{rpm}$ at $4{ }^{\circ} \mathrm{C}$ for $10 \mathrm{~min}$. Betacyanin in the water-extracted fraction was examined with a UV-Visible Spectrometer (DR 5000TM UV-Vis, HACH, Ames, IA, USA) (UV/Vis) at $538 \mathrm{~nm}$. The anthocyanin, total phenolic content (TPC), total flavonoids (TFs), and the DPPH in the ethanol-extract fraction were also determined using UV/Vis. The anthocyanin analysis followed a previous report [24]. Briefly, $0.1 \mathrm{~g}$ of djulis seed powder was extracted with $10 \mathrm{~mL}$ of ethanol. After ethanol extraction, the djulis mixture, which was composed with $60 \%$ ethanol extract, $40 \%$ DD 
water, and $0.1 \% \mathrm{HCl}$, was made. The anthocyanin standards and djulis mixture were tested using UV/Vis at 530 or $657 \mathrm{~nm}$.

The analytical method used for the TPC followed Kujala et al.'s report with minor modifications [25]. That is, $100 \mu \mathrm{L}$ of djulis mixture was mixed with $50 \mu \mathrm{L}$ of FolinCiocalteu reagent in a $1.5 \mathrm{~mL}$ Eppendorf tube for $5 \mathrm{~min}$, to which $1 \mathrm{~mL}$ of $2 \%$ sodium carbonate was subsequently added and mixed for $30 \mathrm{~min}$. The standards of gallic acid $(0$, 50, 100, 150, 200, and $300 \mathrm{ppm}$ ) and $200 \mu \mathrm{L}$ mixture solution from an Eppendorf tube were added into a medium in a 96-well plate analyzed by UV/Vis to determine the TPC. Finally, the TPC of the seed was expressed as $\mathrm{mg}$ of gallic acid equivalents per $100 \mathrm{~g}$ of the seed (mg GAE/100 g). For the TF analysis, the analytical method was slightly modified from Jia's study [26]. In short, $0.5 \mathrm{~mL}$ of the djulis mixture was placed in a $15 \mathrm{~mL}$ centrifuge tube and mixed with $1.5 \mathrm{~mL} 95 \%$ ethanol, $0.1 \mathrm{~mL} 10 \% \mathrm{AlCl}_{3} \cdot 6 \mathrm{H}_{2} \mathrm{O}, 0.1 \mathrm{~mL} 1 \mathrm{M} \mathrm{CH}_{3} \mathrm{COOK}$, and $2.8 \mathrm{~mL} \mathrm{H}_{2} \mathrm{O}$. After mixing for $30 \mathrm{~min}, 200 \mu \mathrm{L}$ of the mixture solution was measured using UV/Vis at $415 \mathrm{~nm}$. The standard solution of quercetin $(0,50,100,150,200,300$, and $500 \mathrm{ppm}$ ) was made for a TF calibration curve. Finally, the TFs from the djulis seed were expressed as mg of quercetin equivalents per $100 \mathrm{~g}$ of the seed (mg QU/100 g). The analytical method used for the DPPH was previously described [27]. A mixture of $120 \mu \mathrm{L}$ of the djulis mixture and $80 \mu \mathrm{L}$ of $0.5 \mathrm{mM}$ DPPH solution was well stirred prior to undergoing a dark reaction for $30 \mathrm{~min}$. The reactant solution and BHT solution as the standard $(0,500$, 1500 , and $2000 \mathrm{ppm}$ ) were examined using UV/Vis at $517 \mathrm{~nm}$. For calculation of the DPPH $(\%)$, the $\%$ inhibition equation was equal to $[\mathrm{A} 0-(\mathrm{A} 1 / \mathrm{A} 0)] \times 100 \%$, where $\mathrm{A} 0$ and $\mathrm{A} 1$ represented the optical density (OD) of the control and the OD of the sample or standards, respectively. Finally, the DPPH (\%) was determined as 100\% inhibition.

\subsection{Analysis of Phenolic Acids and Flavonoids by HPLC/DAD}

A high-performance liquid chromatograph with a diode-array UV-VIS detector (HPLC/DAD, Hitachi Chromaster 5110 pump/Hitachi Chromaster 5420) and a reversed phase $\mathrm{C}_{18}$ HPLC column (ZORBAX Eclipse Plus $\mathrm{C}_{18}, 5 \mu \mathrm{m}$ particle size, I.D. $\times$ L $4.6 \mathrm{~mm}$ $\times 25 \mathrm{~cm}$ ) was used to measure the levels of phenolic acids (gallic acid, chorogenic acid, and 4-hydroxy-3-methoxycinnamic acid) and flavonoids (epicatechin, quercetin, and rutin) (Figure S1). The djulis mixture was filtered using a $0.45 \mu \mathrm{m}$ polytetrafluoroethylene member prior to the injection of $20 \mu \mathrm{L}$ of the extract into a sampling loop. Solvent A ( $99 \% \mathrm{DD}$ water and $1 \%$ acetic acid, $\mathrm{v} / \mathrm{v})$ and solvent $\mathrm{B}(100 \%$ acetonitrile) were used as the mobile phase at a flow rate of $1 \mathrm{~mL} / \mathrm{min}$. The gradient of the two solvents in the mobile phase was maintained at $90 \%$ solvent A for $10 \mathrm{~min}, 82 \%$ solvent A for $14 \mathrm{~min}$, and maintained at $82 \%$ solvent $\mathrm{A}$ for $3 \mathrm{~min}$, followed by being decreased to $70 \%$ solvent $\mathrm{A}$ for $3 \mathrm{~min}$, and retained at $70 \%$ solvent $\mathrm{A}$ for $10 \mathrm{~min}$, and then increased from 70 to $90 \%$ solvent $\mathrm{A}$ for $3 \mathrm{~min}$, and kept at $90 \%$ solvent A for $5 \mathrm{~min}$. The calibration curve was made using external standards ranging from 0 to $500 \mathrm{ppm}$. Quality control followed the methods proposed by the Taiwan Food and Drug Administration, including the solvent and sample blank, limits of detection, recovery rate, and the signal-to-noise ratio.

\subsection{The Tests of the Thermal Effects}

The djulis seed of $1 \mathrm{~g}$ was heated in an oven (DO45, DENG YNG, New Taipei, Taiwan) at an oven temperature of 46,55 , or $77^{\circ} \mathrm{C}$ and the contact time was set as 5,10 , or $15 \mathrm{~s}$. The thermal-treated and non-thermal control (room temperature) seeds were extracted to be detected for levels of betacyanin, anthocyanin, TFCs, TFs, and DPPH.

\subsection{Cell Viability Assays of the THP-1 Cells}

The human monocyte cell line, THP-1, was cultured with RPMI 1640 medium (Gibco, Life Technologies, Carlsbad, CA, USA), 10\% fetal bovine serum (Gibco, Life Technologies, Carlsbad, CA, USA), and 1\% penicillin/streptomycin (Gibco, Life Technologies, Carlsbad, CA, USA) at $37{ }^{\circ} \mathrm{C}, 5 \% \mathrm{CO}_{2}$, and $95 \%$ humidity. The THP-1 cells were resuspended in fresh media at a concentration of $2 \times 10^{6} / \mathrm{mL}, 0.1 \mathrm{~mL} /$ well in 96-well plates and reacted 
with 10\% Alamar Blue reagent for $30 \mathrm{~min}$. The THP-1 cell viability was determined after exposure of djulis and a carboxylated single-wall carbon nanotube (SWCNT-COOH), which is an engineered nanomaterial that can easily induce oxidative stress and inflammatory responses in in vitro systems, for 24 and $48 \mathrm{~h}$. The fluorescence intensity of the stained cells was measured using excitation at $530-560 \mathrm{~nm}$ and emissions at $590 \mathrm{~nm}$. Data were calculated as percent $(\%)$ viability relative to the untreated control, which was set at $100 \%$. Three replicates were performed for each of the concentrations.

\subsection{Intracellular ROS Staining of THP-1 Cells}

After pretreatment with/without $100 \mu \mathrm{g}$ of the djulis seed extract overnight, the THP-1 cells were resuspended in fresh media at a concentration of $2 \times 10^{6} / \mathrm{mL}, 0.1 \mathrm{~mL} /$ well in 96-well plates and reacted with $20 \mathrm{mM}$ of $2^{\prime}, 7^{\prime}$-dichlorodihydrofluorescein diacetate (DCFH-DA) probe (Invitrogen ${ }^{\mathrm{TM}}$, Thermo Fisher Scientific, Waltham, MA, USA) for $30 \mathrm{~min}$. Following treatment with SWCNT-COOH, the fluorescence intensity of the stained cells was measured at $485 \mathrm{~nm}$ (excitation) and $527 \mathrm{~nm}$ (emission) to determine the ROS levels. Cell viability was determined using an Alamar Blue assay. Following treatment with SWCNT-COOH at all concentrations for $48 \mathrm{~h}$, the fluorescence intensity of the stained cells was measured based on the excitation at $485 \mathrm{~nm}$ and emissions with the $535 \mathrm{~nm}$. Data were calculated as percent (\%) relative to untreated control, which was set at $100 \%$. Three replicates were performed for each of the concentrations.

\subsection{Statistical Analysis}

All of the measurements were higher than the limit of detection. Non-parametric analyses such as Wilcoxon sign rank tests were used to examine the induced folds of bioactive compounds in the NTP-treated djulis seed compared with the untreated control. The significant differences in the induced folds of bioactive compounds in the djulis seed were tested to compare the air-NTP $(n=3)$ and $\mathrm{N}_{2}$-NTP $(n=6)$ using Wilcoxon sign rank tests. All statistical analyses were performed using SPSS Version 12.0 for Windows (SPSS IBM Inc., Armonk, NY, USA).

\section{Results}

\subsection{Surface Analysis of Djulis Seed after NTP Treatment}

Figure 1 shows the OES spectra from air-NTP and $\mathrm{N}_{2}$-NTP. Different OES spectra were found in air-NTP (Figure 1A) and $\mathrm{N}_{2}$-NTP (Figure 1B). Figure 1A shows the similar OES spectra at 600 and $800 \mathrm{~W}$ of input power used to generate several similar nitrogen-induced active species during air-NTP. Figure $1 \mathrm{~B}$ shows the similar OES spectra at 600 and $800 \mathrm{~W}$ generated from $\mathrm{N}_{2}$-NTP. The FTIR spectrum on the surface of the djulis seed before the NTP treatment is shown in Figure 2. Several functional groups, including poly-saccharides (3200-3500 cm $\left.\mathrm{cm}^{-1}\right)$, a carbonyl group $(\mathrm{C}=\mathrm{O})\left(1731 \mathrm{~cm}^{-1}\right)$, aromatics $\left(1605 \mathrm{~cm}^{-1}\right)$, and an ether group (C-O-C) $\left(1166 \mathrm{~cm}^{-1}\right)$, were found in the FTIR spectra on the seed surface. The similar results of the functional groups on the NTP-treated seed surface were shown in Figure S2. Surface morphological images of the djulis seed before and after NTP treatment were examined using SEM (Figure S3). The seed surface before NTP treatment presented as a compact, solid, rough, and naturally morphological structure. After treatment with air NTP, the seed surface changed due to surface etching generated by plasma and presented as an eroded structure with a smooth, soft surface. 
(A) Air-NTP

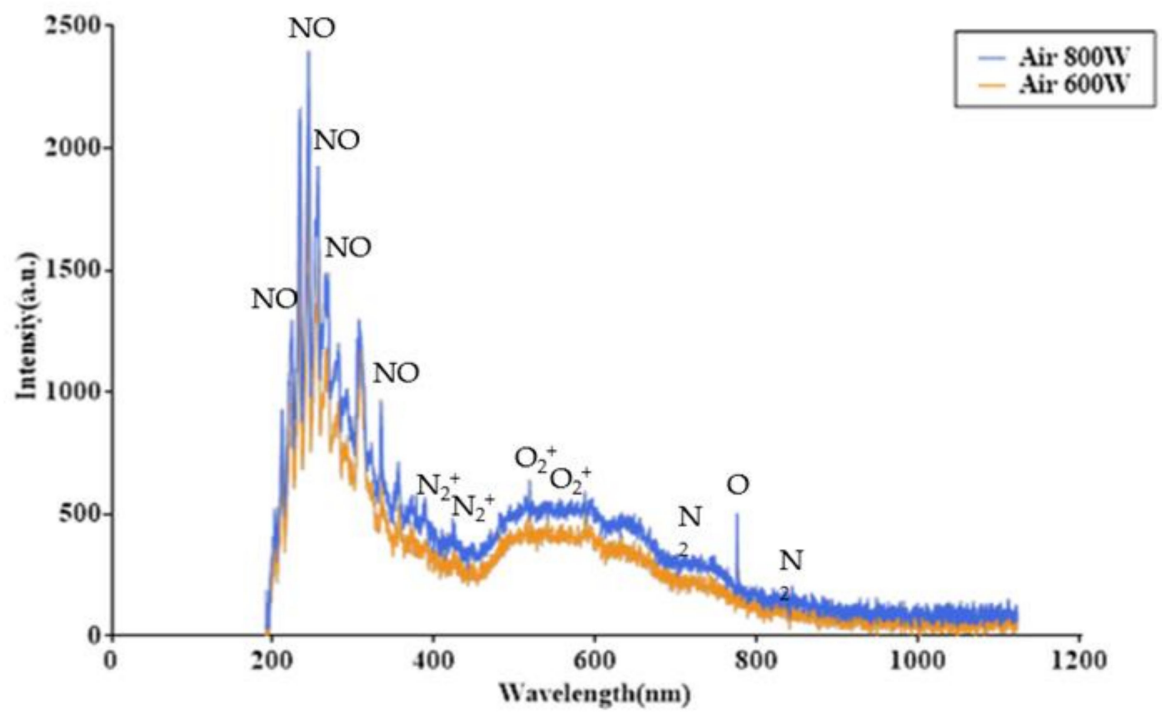

(B) $\mathrm{N}_{2}-\mathrm{NTP}$

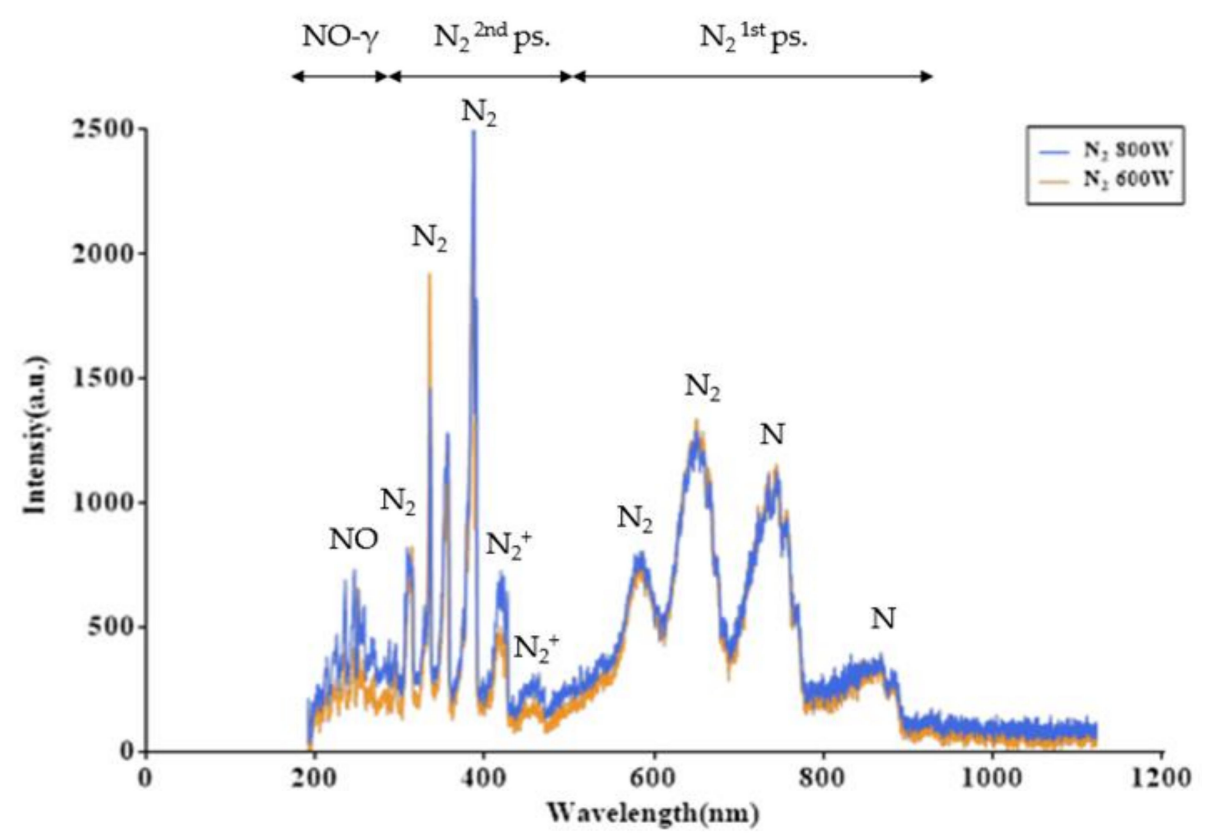

Figure 1. Optical analysis of NTP and djulis seeds: (A) the OES (optical emission spectroscopy) spectrum after air atmospheric plasma (air-NTP) and (B) the OES spectrum after nitrogen gas atmospheric plasma $\left(\mathrm{N}_{2}-\mathrm{NTP}\right)$ treatment. 


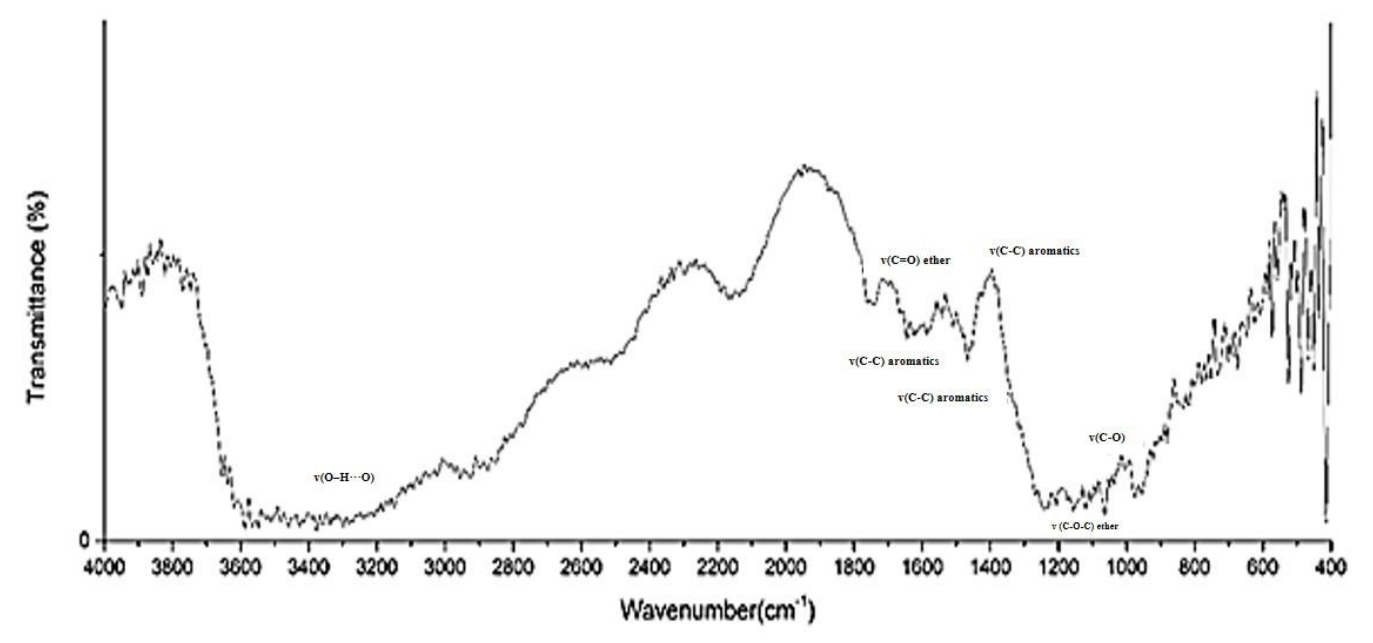

Figure 2. The functional groups of FTIR spectrum on the surface of the djulis seed.

\subsection{Bioactive Compounds in Djulis Seed}

The natural bioactive compound levels in djulis seed, including betacyanin, anthocyanin, TPCs, TFs, and DPPH, are shown in Table 2. The natural betacyanin and anthocyanin bioactive compounds used were 9.50 and $24.5 \mathrm{mg} / 100 \mathrm{~g}$ (median) and 4.00 and $25.7 \mathrm{mg} / 100 \mathrm{~g}$ (median), purchased in the NPUST retail store obtained from SAF/NPUST and directly harvested from SAF/NPUST farms, respectively. The medians of the TPC were 35.9 and $88.2 \mathrm{mg} \mathrm{GAE} / 100 \mathrm{~g}$ for the seeds from the retail store and SAF/NPUST, respectively. The median levels of TFs were $1.79 \mathrm{mg}$ QU/100 $\mathrm{g}$ for the retail store and $5.25 \mathrm{mg}$ QU/100 $\mathrm{g}$ for SAF/NPUST farms. The median percentage of DPPH was 79.1\% for the retail store and $86.0 \%$ for SAF/NPUST farms. The levels of bioactive compounds except for betacyanin in djulis seed harvested from the NPUST farms were significantly higher than those in the seed obtained from the retail store $(p<0.001)$.

Table 2. Levels of natural bioactive compounds in the djulis seed without the NTP treatment.

\begin{tabular}{|c|c|c|c|c|c|c|}
\hline \multirow[b]{2}{*}{ Compounds } & \multicolumn{3}{|c|}{$\begin{array}{l}\text { Air-NTP }(\mathrm{n}=3)^{a} \\
\quad \text { (Retail Store) }\end{array}$} & \multicolumn{3}{|c|}{$\begin{array}{c}\mathrm{N}_{2}-\mathrm{NTP}(\mathrm{n}=6)^{\mathrm{b}} \\
\text { (SAF/NPUST) }^{\text {SAF }}\end{array}$} \\
\hline & Range & Median & Mean & Range & Median & Mean \\
\hline $\begin{array}{l}\text { Betacyanin } \\
(\mathrm{mg} / 100 \mathrm{~g})\end{array}$ & $9.50-9.06$ & 9.50 & $9.50 \pm 0.005$ & $3.99-4.03$ & 4.00 & $4.01 \pm 0.019$ \\
\hline $\begin{array}{l}\text { Anthocyanin } \\
(\mathrm{mg} / 100 \mathrm{~g})\end{array}$ & $24.5-25.6$ & 24.5 & $24.8 \pm 0.633$ & $25.3-25.8$ & 25.7 & $25.6 \pm 0.633$ \\
\hline $\begin{array}{l}\text { Total phenolic content } \\
\quad(\mathrm{mg} \text { GAE } / 100 \mathrm{~g})\end{array}$ & $34.6-36.1$ & 35.9 & $35.55 \pm 0.830$ & $86.8-89.0$ & 88.2 & $88.0 \pm 1.12$ \\
\hline $\begin{array}{l}\text { Total flavonoids } \\
(\mathrm{mg} \text { QU / } 100 \mathrm{~g})\end{array}$ & $1.39-1.89$ & 1.79 & $1.69 \pm 0.265$ & $4.85-5.66$ & 5.25 & $5.25 \pm 0.401$ \\
\hline $\begin{array}{c}\mathrm{DPPH}^{\mathrm{c}} \\
\text { (Percentage, \%) }\end{array}$ & $72.5-81.2$ & 79.1 & $77.6 \pm 4.52$ & $85.5-86.2$ & 86.0 & $85.9 \pm 0.355$ \\
\hline
\end{tabular}

${ }^{a}$ The djulis seed purchased from the retail store at NPUST. ${ }^{b}$ The djulis seed harvested from the sustainable agricultural farms at NPUST. ${ }^{c}$ 2,2-diphenyl-1-picrylhydrazyl radical scavenging effect.

\subsection{Variations in Bioactive Compounds Treated Using NTP}

The levels of betacyanin, anthocyanin, and DPPH in NTP-treated djulis seed varied as compared with those in the untreated control (Figure 3). The betacyanin concentrations in $\mathrm{N}_{2}$-NTP-treated seed ranged from 1.06- to 1.21-fold higher than those in the untreated seed $(p<0.01)$ (Figure 3A). Inversely, the betacyanins in the air-NTP-treated djulis seed were significantly lower than those in the untreated control $(p<0.01)$. Figure $3 \mathrm{~B}$ shows the significantly elevated levels of anthocyanin in the NTP-treated seed as compared to the untreated sample for methods B, C, E, F, and I after the air-NTP treatment (increased 
1.02-1.21 fold, $p<0.001$ ) as well as methods A, B, D, E, G, H, and I after $\mathrm{N}_{2}$-NTP treatment (increased 1.03-1.17 fold, $p<0.001$ ). In terms of the antioxidant activity, such as DPPH, there were significantly higher magnitudes in the air-NTP-treated seed with methods A, $\mathrm{D}$, and $\mathrm{E}$ (increased 1.04-1.10 fold, $p<0.001$ ) as well as in the $\mathrm{N}_{2}-\mathrm{NTP}$-treated seed with methods $\mathrm{H}$ to $\mathrm{K}$ (increased 1.02-1.07 fold, $p<0.001$ ) as compared with the untreated seed.

(A) Betacyanin

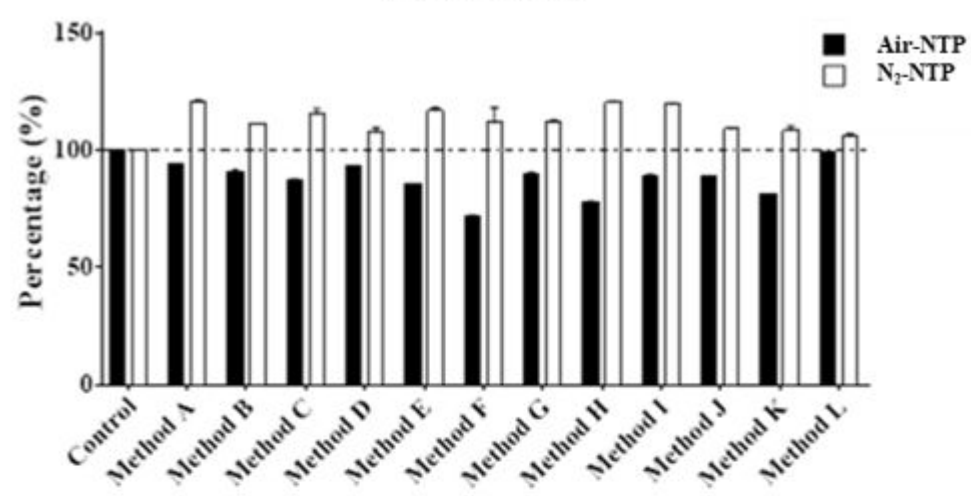

(B) Anthocyanin

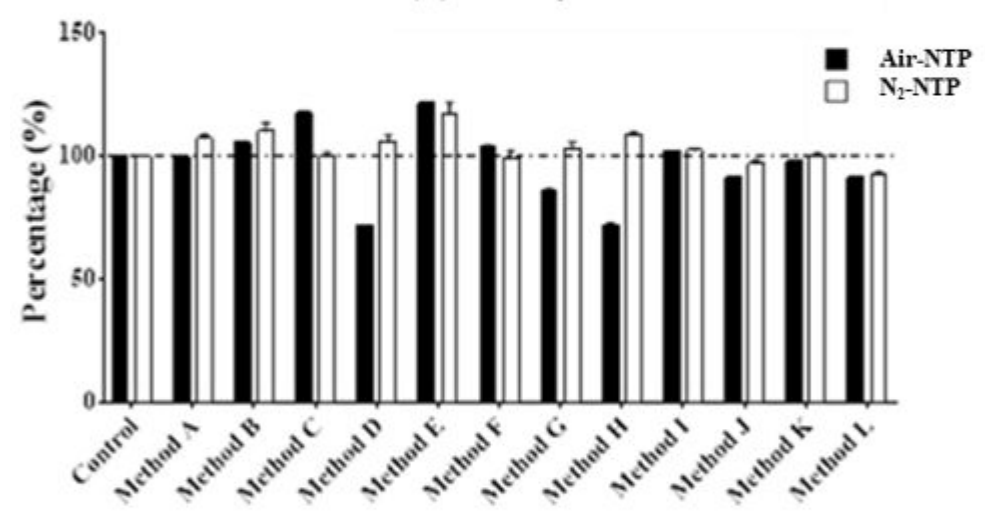

(C) DPPH

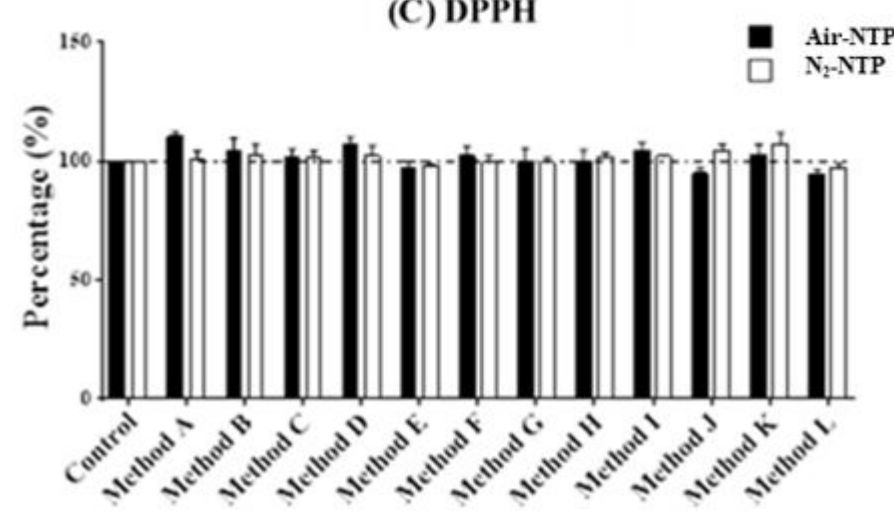

Figure 3. Variations in betacyanin (A), anthocyanin (B), and DPPH radical scavenging effects (C) in djulis seed after air-NTP or $\mathrm{N}_{2}$-NTP treatment compared with the untreated control.

From Figure 4A, TPCs was significantly increased from 1.04 to 1.23 fold in all of the $\mathrm{N}_{2}$-NTP-treated seed and significantly increased (1.04-1.16 fold) in the air-NTP-treated seed with methods A, I, and J as compared with the untreated control $(p<0.001)$. Figure $4 \mathrm{~B}$ shows that, only method A in the air-NTP-treated seed and method B in the $\mathrm{N}_{2}-\mathrm{NTP}$-treated seed showed significant increases in the TFs by $1.21(p<0.01)$ and $1.01(p=0.033)$ fold, respectively, compared with the untreated samples. The profiles for djulis extract are shown in Figures S4-S6. The most predominant compounds in TPCs and TFs were gallic acid 
and rutin, respectively (Figure 5). The concentrations of gallic acid were $25.7 \pm 1.24 \mu \mathrm{g} / \mathrm{g}$ in the retail store sample and $36.7 \pm 2.58 \mu \mathrm{g} / \mathrm{g}$ in the SAF/NPUST sample, and the rutin levels were $27.3 \pm 2.07 \mu \mathrm{g} / \mathrm{g}$ in the retail store sample and $26.6 \pm 2.16 \mu \mathrm{g} / \mathrm{g}$ in the SAF/NPUST sample. For air-NTP treatment, the fold increase in gallic acid ranged from 1.02 to 1.24 , and the fold increase of rutin ranging between 1.01 and 1.44 was not significantly increased as compared to that in the untreated controls. For $\mathrm{N}_{2}-\mathrm{NTP}$, the levels of gallic acid (1.10-1.35 fold) and rutin (1.09-1.40 fold) in the $\mathrm{N}_{2}$-NTP treated seed were higher than those in the control, but the results were not statistically significant $(p>0.05)$.

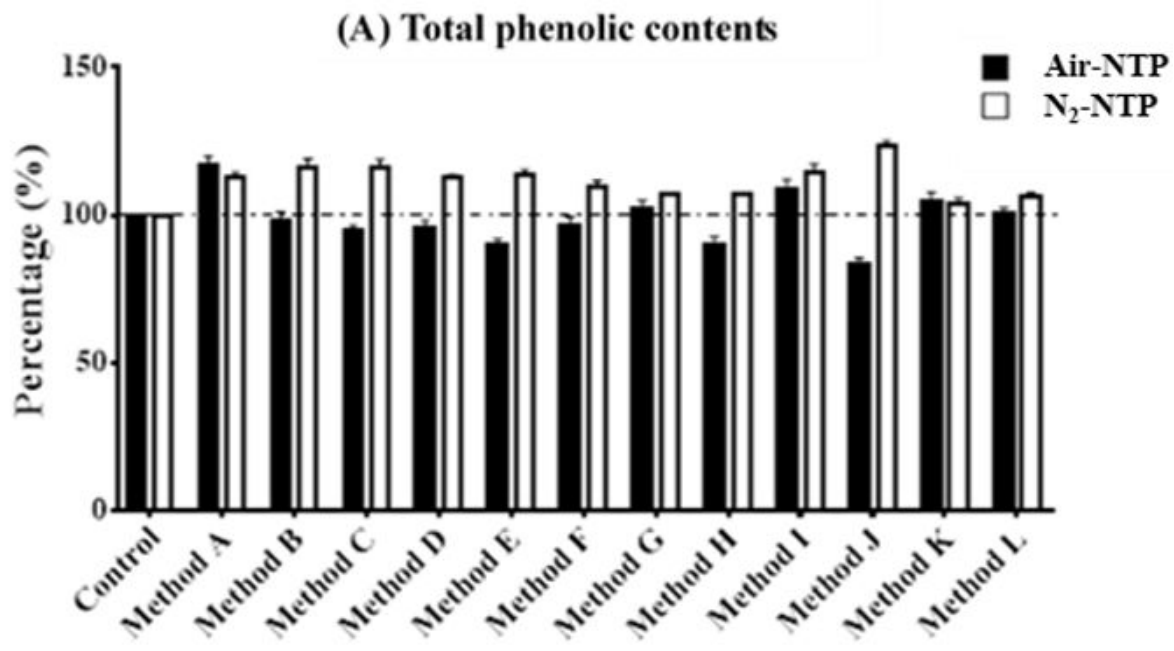

(B) Total flavonoids

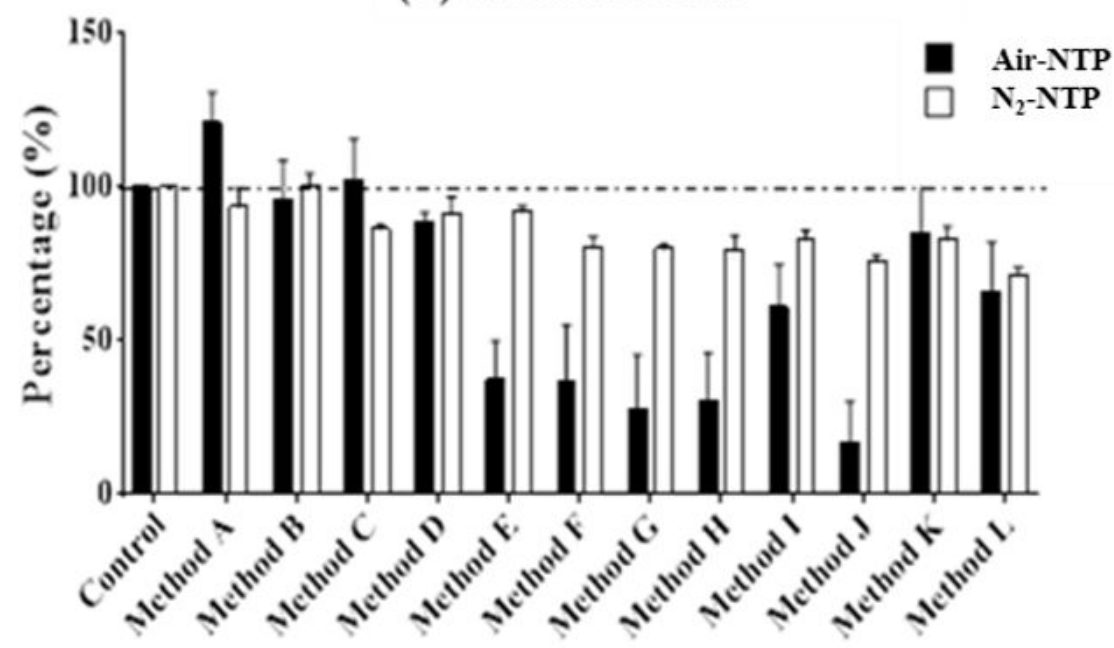

Figure 4. Levels of phenolic acids and flavonoids in the NTP-treated and untreated djulis seeds shown as total phenolic content in the NTP-treated seeds compared with the untreated control: (A) flavonoids in NTP-treated seeds compared with the untreated seeds (control) and (B) levels of gallic acid and rutin in seeds before and after NTP treatment. 
(A) Air-NTP

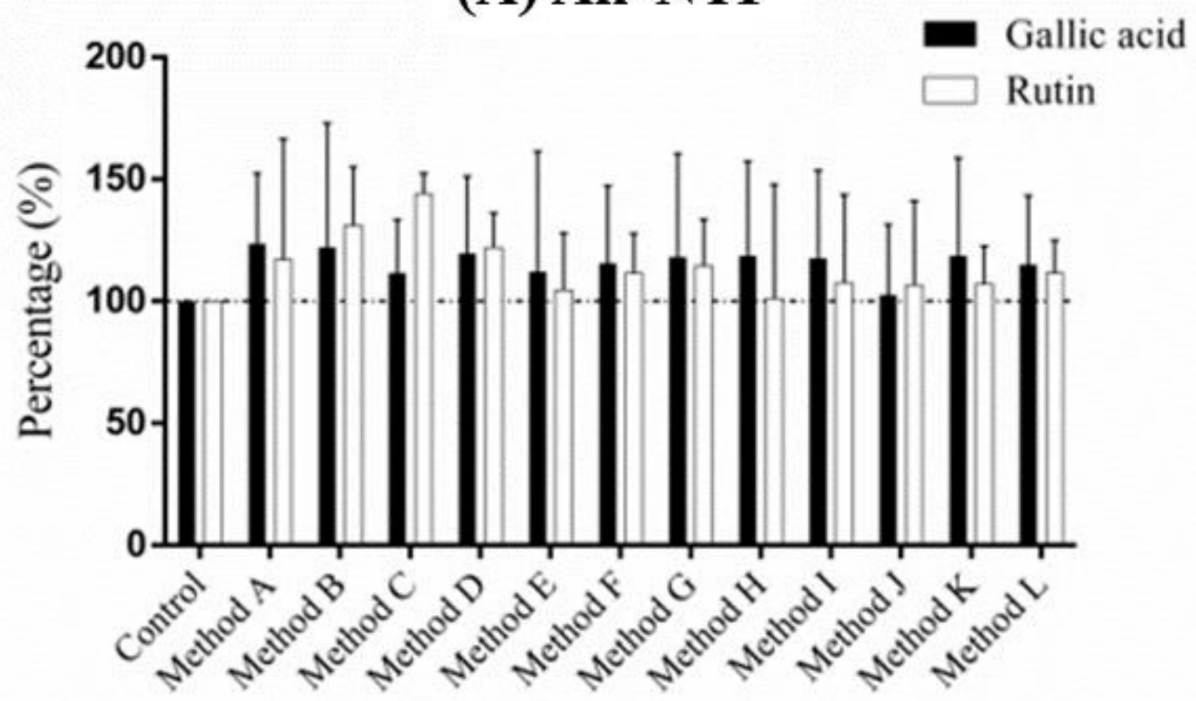

(B) $\mathrm{N}_{2}-\mathrm{NTP}$

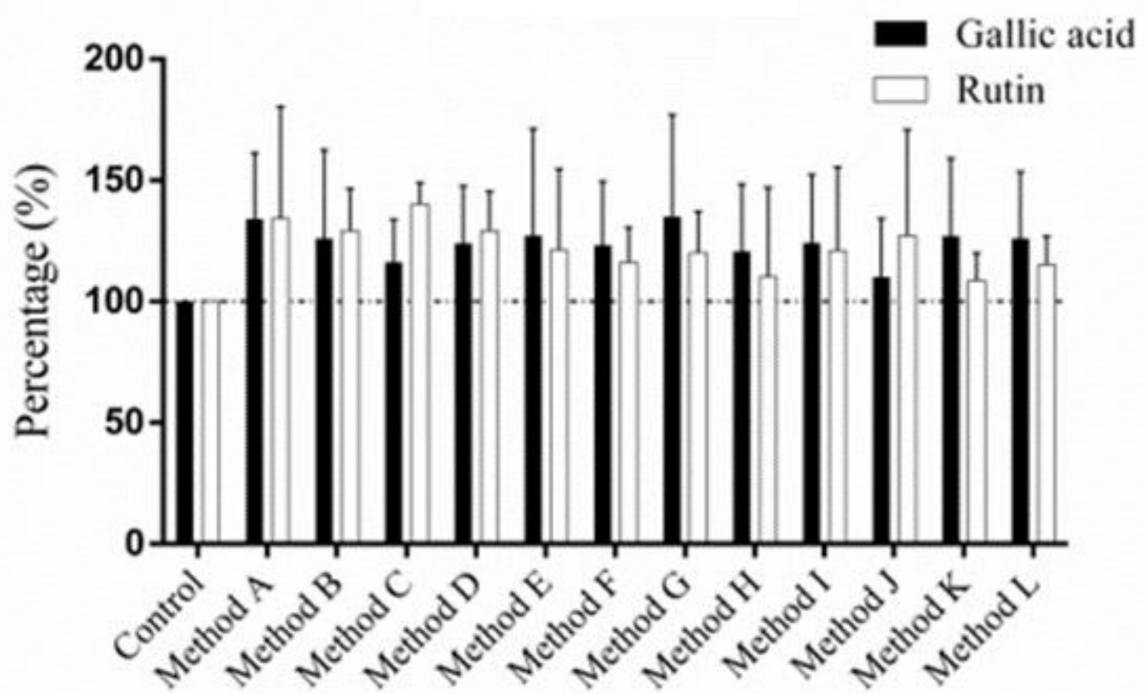

Figure 5. Levels of gallic acid and rutin in the seeds before and after NTP treatment: (A) air-NTP treatment and (B) $\mathrm{N}_{2}-\mathrm{NTP}$ treatment.

\subsection{Changes of Bioactive Compounds on the Djulis Seed after Thermal Treatment}

Figure 6 showed the changes of bioactive compounds on the djulis seed before and after thermal treatment. Compared with the non-thermal control (room temperature), the fold increases of bioactive compounds including betacyanin, anthocyanin, TFCs, TFs, and $\mathrm{DPPH}$ from the djulis seed extract in the thermal-treated samples were not significantly different in Figure 6A-C. 
(A)

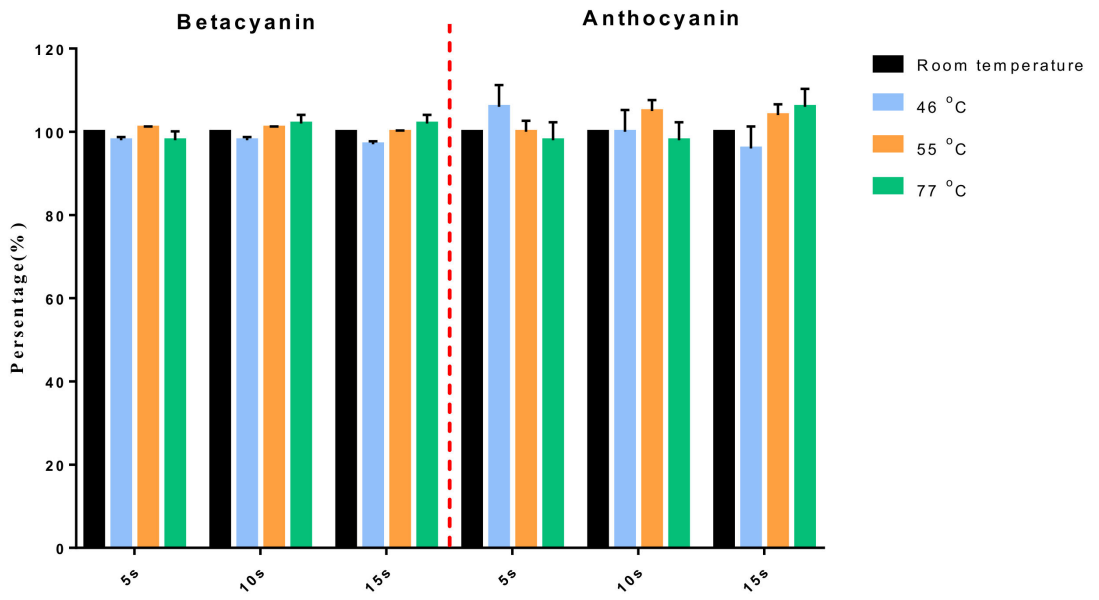

(B)
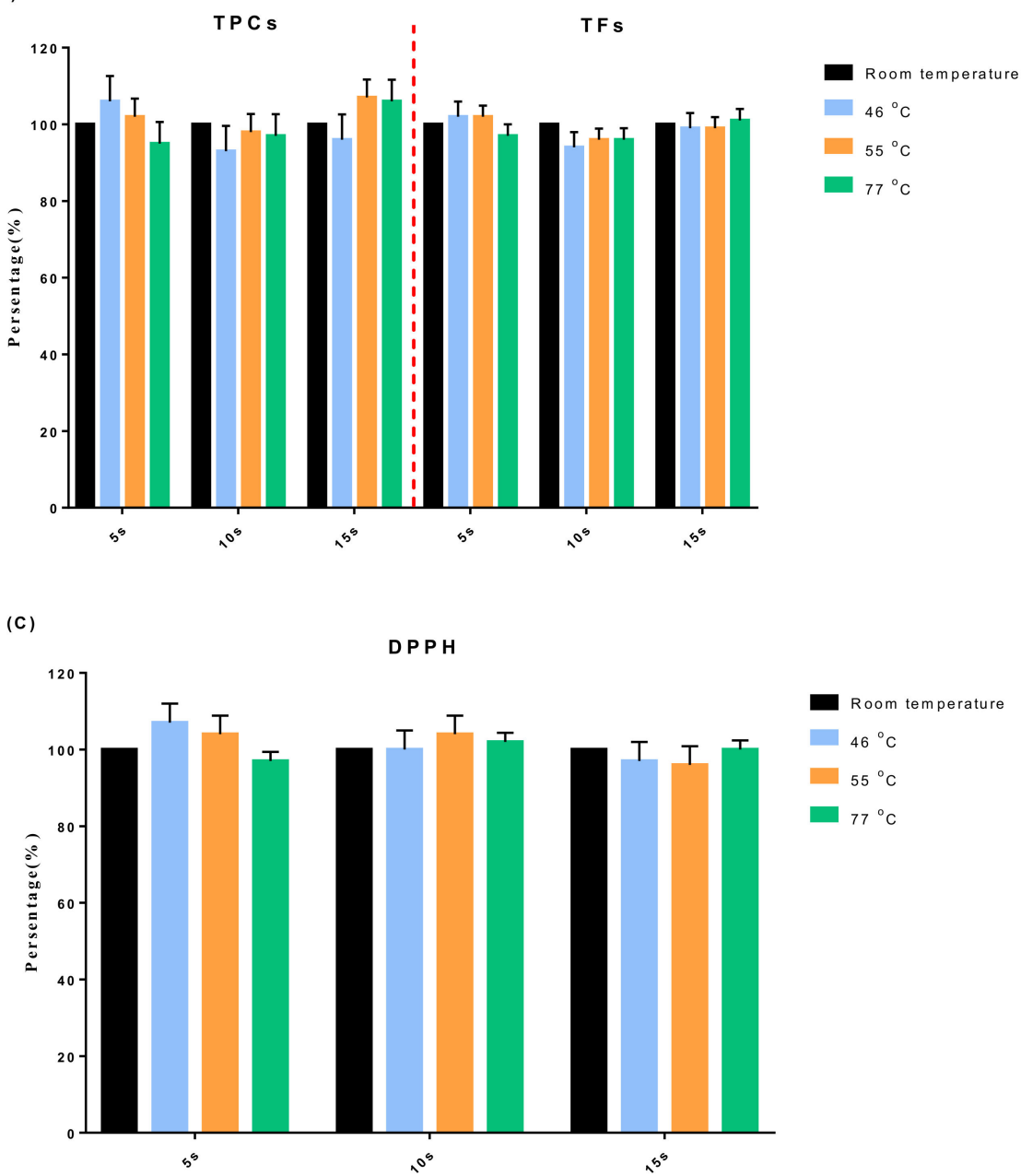

Figure 6. Examination of thermal effects on the djulis seeds heated by oven. The oven temperature was controlled at room temperature and 46,55 , and $77^{\circ} \mathrm{C}$ and the contact times tested were 5,10 , and $15 \mathrm{~s}$. The fold increases of bioactive compounds of the djulis seed under the thermal treatment were obtained over those in the non-thermal control (room temperature): (A) betacyanin and anthocyanin; (B) TFCs and TFs; and (C) DPPH. 


\subsection{ROS Production with Cotreatment of Djulis Seed Extract and SWCNT-COOH in THP-1 Cells}

In comparison with the control group, both the djulis seed extract (1-100 $\mu \mathrm{g})$ and SWCNT-COOH $(0.001-0.01 \mu \mathrm{g} / \mathrm{L})$ did not influence the THP-1 cell viability (Figure S7). However, $0.001-0.01 \mu \mathrm{g} / \mathrm{L}$ of SWCNT-COOH significantly increased ROS production in the THP- 1 cells after exposure of the cell to the nanoparticles for $6 \mathrm{~h}$, as compared with the control group (Figure S8). In order to determine whether the djulis seed extract and its bioactive compounds inhibit SWCNT-COOH-induced ROS production, the THP-1 cells were pretreated with/without $100 \mu \mathrm{g}$ djulis seed extract overnight, followed by the addition of $0.1 \mu \mathrm{g} / \mathrm{L}$ SWCNT-COOH for $6 \mathrm{~h}$. Compared with the $0.1 \mu \mathrm{g} / \mathrm{L}$ SWCNT-COOH treatment group, the result revealed that djulis seed extract could inhibit SWCNT-COOH-induced ROS production in THP-1 cells (Figure S9).

\section{Discussion}

Djulis is a local flora in Taiwan. Although several Taiwanese scientists have found that the nutrition, abundant TFs and TPC (particularly rutin and gallic acid), and antioxidants are good for human health, few scientists outside Taiwan are aware of this valuable vegetation $[2,15,17,18]$. This study reiterates the value of djulis seed, and an attempt is made to examine the changes in the natural bioactive compounds in seed after NTP treatment. Table 2 shows levels of natural bioactive compounds in the djulis seed without NTP treatment. Few reports have focused on the bioactive compounds in djulis seed. A previous study showed a lower magnitude of TPCs (5.67-6.42 mg GAE/100 g) and TFs (0.472-0.572 mg QU/100 g) in djulis hulls [15], compared with those from our results for djulis seed. Taiwanese nutritionists emphasize the content of betacyanin and anthocyanin in djulis seed. Tsai et al. (2010) indicated that betacyanin can be separated and identified using liquid chromatography/ion trap mass spectrometry for four species of betacyanin, including betanin, isobetanin, amaranthine, and isoamaranthin. The two bioactive compounds in betanin and isobetanin contributed $73.9 \%$ of betacyanin necessary for DPPH scavenging as the major source of the antioxidants [18]. Huang et al. (2019) also revealed that djulis hulls are a potential source for natural antioxidants in food due to their inhibitory effects on cumulative concentrations of nitric oxide and prostaglandin estradiol [15]. In both previous and recent studies, scientists have found various abundant bioactive compounds and their associated antioxidants in djulis.

Although treatment with CAP and NTP is common in agricultural applications, most seed studies have concentrated on the notably positive improvements in seed germination, shoot and root growth, and the growth of young seedlings after CAP or NTP treatment $[8,9,26,27]$. Previous reports referred to the factors influencing germination in relation to different types of plasma (e.g., the atmospheric pressure dielectric barrier charge (DBD) and low-pressure radiofrequency (RF) plasma) and the plasma working gases (e.g., air, oxygen, nitrogen, and argon) $[8,25,27]$. An air-CAP treatment was found to notably accelerate the germination of cotton in comparison with an argon-CAP treatment, where the contact time of air-CAP was positively correlated with the hydrophilicity of the cotton seed surface and water uptake [8]. To the best of our knowledge, few studies have considered the impact of CAP or NTP treatment on variations in bioactive compounds in seed, including djulis. In the present study, air-NTP and $\mathrm{N}_{2}-\mathrm{NTP}$ treatment of djulis seed was carried out to measure the temperature on the djulis seed surface at temperatures ranging between 46 and $77^{\circ} \mathrm{C}$, which is slightly higher than the temperature used for CAP treatment $\left(27^{\circ} \mathrm{C}\right.$ or $\left.300 \mathrm{~K}\right)$. Compared with other seed studies where CAP treatment was used on seed for a few minutes $[8,9,26,27]$, in the present study, air-NTP or $\mathrm{N}_{2}-\mathrm{NTP}$ was used to treat djulis seed to induce changes in bioactive compounds in a few seconds. In the present study, NTP treatment affected the bioactive compound levels, such as betacyanins, anthocyanins, phenolic acids, and flavonoids, in djulis seed as compared with the untreated seed. According to our findings, the radical scavenging ability of DPPH in the untreated, air-NTP-treated, and $\mathrm{N}_{2}$-NTP-treated seeds were at quite high levels ranging from $75 \%$ to 
$91 \%$. The positive and negative effects on the bioactive compounds in the djulis seed after NTP treatment appeared to depend on the usage of plasma gas (air and $\mathrm{N}_{2}$ ), the plasma input power $(600$ and $800 \mathrm{~W})$, contact time $(0.51-1.02 \mathrm{~s})$, and temperature $\left(46-77^{\circ} \mathrm{C}\right)$ in this study (Figures 3 and 4). The findings of the present study were mainly dependent on the plasma working gas (air and $\mathrm{N}_{2}$ ) and were slightly independent of the contact temperature and time in terms of influencing the bioactive compound content in djulis seed. The results showed that bioactive compound levels, particularly betacyanin and TPCs, were significantly and positively related to $\mathrm{N}_{2}$-NTP treatment and, in contrast, were negatively correlated with the air-NTP treatment. This is a new finding, where changes in the natural bioactive compounds of the seed could occur in a few seconds due to NTP treatment especially in the case of $\mathrm{N}_{2}$-NTP treated djulis seed to activate the content of betacyanin, betacyanins, anthocyanins, TFCs, gallic acid, and rutin. It is still unknown why there were inversely dramatic differences in the amount of activated bioactive compounds in the air-NTP and $\mathrm{N}_{2}$-NTP samples.

Our results indicate that plasma etching may be related to surface damage to the djulis seed, where etching and damage were found on the pericarpal surface of air-CAPtreated quinoa seed [25]. NTP or CAP accelerate the water uptake mainly through the generation of UV radiation, ROS and RNS, as well as specific electric currents due to plasma etching $[8,9,25-27]$. Several reports have also shown an eroded structure or surface etching generated in NTP-treated seeds, such as brown rice [26], cotton seed [8], and quinoa [25], intended to improve seed germination rates and seeding growth. It has been revealed that plasma etching on the seed surface may be associated with improvements in germination or may activate various biochemical processes that cause new functional groups on the outermost coat layers of seeds $[25,28]$, which, based on our findings, may also be related to increased levels of betacyanin, anthocyanin, TPCs, rutin, and gallic acids in $\mathrm{N}_{2}$-NTP-treated djulis seed. No thermal effects were found in the present study due to thermal treatment in a few seconds.

In the present study, bioactive compounds, with the exception of TFs, were enhanced by the $\mathrm{N}_{2}$-NTP treatment, and these chemicals were inhibited by the air-NTP treatment under most testing conditions. According to the different patterns in the OES spectra between the air-NTP and $\mathrm{N}_{2}$-NTP treatment groups shown in Figure 1, these results were inferred to be due to the different reactive species generated by treatment of air-NTP and $\mathrm{N}_{2}$-NTP. Nitrogen oxide species (NO- $\gamma$ ) from 200 to $300 \mathrm{~nm}$ possibly were generated by $\mathrm{N}_{2-}$ NTP plasma jet in the OES spectra, mainly due to the collision of the RNS in $\mathrm{N}_{2}-\mathrm{NTP}$ with the surrounding air [28,29]. Figure 1 shows that differences in the intensities of $\mathrm{NO}, \mathrm{N}_{2}$, and $\mathrm{N}_{2}{ }^{+}$on the OES spectra were also found between the air-NTP and $\mathrm{N}_{2}$-NTP treatment groups. The different species of reactive substances in plasma ionizing gas were induced by plasma discharge with the different working gases. Nitrogen-based reactive species, such as nitrogen dioxide $\left(\bullet \mathrm{NO}_{2}\right)$ and nitric oxide $(\bullet \mathrm{NO})$, which are RNS, and nitrous oxide $\left(\mathrm{N}_{2} \mathrm{O}\right)$, nitrogen trioxide $\left(\mathrm{NO}_{3}\right)$, peroxynitrite $\left(\mathrm{ONOO}^{-}\right)$, and dinitrogen tetroxide $\left(\mathrm{N}_{2} \mathrm{O}_{4}\right)$, which are reactive gases, were generated by air-NTP or $\mathrm{N}_{2}-\mathrm{NTP}$ treatment; while oxygen-based reactive species, including ROS generated by air-NTP or $\mathrm{O}_{2}$-NTP included hydrogen peroxide $\left(\mathrm{H}_{2} \mathrm{O}_{2}\right)$, ozone $\left(\mathrm{O}_{3}\right)$, hydroxyl, singlet oxygen $\left({ }^{1} \mathrm{O}_{2}\right)$, hydroxyl radical $(\bullet \mathrm{OH})$, and superoxide $\left(\mathrm{O}_{2}{ }^{-} \bullet\right)[30,31]$.

The findings of the present study showed that air-NTP treatment inhibited the performance of certain bioactive compounds in the djulis seed, and $\mathrm{N}_{2}$-NTP enhanced the levels of bioactive compounds. In a quinoa study [13], ROS and RNS generated etching and damage on the seed surface, in turn modifying chemical and morphological effects on the surface and increasing absorption of nitrate functional groups on the seed. $\mathrm{N}_{2}-\mathrm{NTP}$ is intended to generate a greater amount of UV radiation and NOx than air-NTP [12]. In this study, various nitrogen species were produced after air-NTP, as shown in Figure 1A. If the findings from the Gómez-Ramírez's study are true [13], in the present study, more abundant RNS may have been activated on the surface of the djulis seed after the $\mathrm{N}_{2}$-NTP treatment as compared with the air-NTP treatment. A large amount of RNS and nitrogen 
functional groups may have been diffused into the interior of the djulis seed that in turn affected the levels of bioactive compounds and antioxidant properties. In a comet assay conducted in a previous study [12], no significant differences in DNA damage in soybean seeds were found between a negative control (the untreated control) and an air-CAP treatment group. Inversely, $\mathrm{N}_{2}$-CAP treatment induced notable and significant DNA damage similar to that in the positive control (the untreated control with addition of zeocin $5 \mathrm{mg} / \mathrm{L}$ for $1 \mathrm{~h}$ ) compared with the negative control. Nitrogen species also possibly penetrated the djulis seed surface and affected the DNA on the chromosome after the NTP treatment. A Korean study revealed that PAW treatment of tomato seedlings enhanced plant growth, generated ROS and RNS, induced inflammation, activated defense hormones, such as salicylic acid and jasmonic acid, and induced pathogenesis-related genes [10]. $\mathrm{N}_{2}$-NTP caused DNA damage easily to further activate defense systems such as antioxidant reactions compared with air-NTP. This may explain the enhancement of bioactive compounds in the djulis seed after treatment with $\mathrm{N}_{2}$-NTP. In a recent study, treating soybean seed with low-dose air $/ \mathrm{O}_{2}$-NTP significantly promoted the Krebs cycle and switched on oxygenic seed germination metabolism from the anoxygenic status. Inversely, high doses of $\mathrm{N}_{2}$-NTP significantly weakened the Krebs cycle, increased lactate and alcohol dehydrogenase, and caused anoxygenic metabolism [12]. According to a previous report [12], $\mathrm{N}_{2}-\mathrm{NTP}$ may activate anoxygenic metabolism and in turn, may enhance activation of betacyanin, anthocyanin, TPCs, rutin, and gallic acids due to damage to the djulis seed that activates a protection mechanism after plasma etching. Prior to the germination of seeds, it is still unknown what happens (e.g., mechanism) in terms of changes in bioactive compounds after air-NTP or $\mathrm{N}_{2}$-NTP treatment on the seed surface due to lack of evidence in current reports.

In this study, it was posited that djulis seed extract may scavenge the free radical, ROS, and RNS in human monocytes, and these findings may be potential on djulis seed extract after air-NTP or $\mathrm{N}_{2}$-NTP treatment. Figures S7 and S8 show that, low doses $(0.01-0.100 \mu \mathrm{g} / \mathrm{L})$ of SWCNT-COOH activate the responses of oxidative stress while no cytotoxic effects are found at these doses. Our results also show that the pretreatment with djulis seed extract overnight could inhibit the expression of oxidative stress after THP-1 cells are exposed to SWCNT-COOH at low doses of $0.100 \mu \mathrm{g} / \mathrm{L}$ (Figure S9). According to a previous study [32], in vitro and in vivo exposure to SWCNT-COOH induced oxidative stress and generated ROS. Exposure of THP-1 cells to SWCNT caused cytotoxicity, genotoxicity, DNA methylation, and inflammatory responses at $10-100 \mu \mathrm{g} / \mathrm{mL}[33,34]$. Our results show the activation of ROS production in human macrophage-differentiated THP- 1 cells at low doses of 0.001$0.100 \mu \mathrm{g} / \mathrm{L}$ without cytotoxicity. With overnight pretreatment of djulis seed extract, the generation of ROS could be inactivated in THP-1 cells. Based on the DPPH results from air-NTP and $\mathrm{N}_{2}-\mathrm{NTP}$, high ROS scavenging effects occurred, and no significant differences were found among the untreated, air-NTP-treated, and $\mathrm{N}_{2}$-NTP-treated seed. It is thus possible to infer that NTP-treated djulis seed extract could inhibit ROS production or prevent ROS generation particularly in the case of $\mathrm{N}_{2}-\mathrm{NTP}$. This may enhance free radical scavenging and lead to improvements in human health. Further studies are encouraged in the future.

\section{Conclusions}

The findings of the present study indicated that several natural bioactive compounds, betacyanin, anthocyanin, TPC, gallic acid, and rutin, which have potential antioxidant abilities in djulis seed, were activated by $\mathrm{N}_{2}$-NTP treatment and inhibited by air-NTP treatment. Under most testing conditions including air-NTP and $\mathrm{N}_{2}-\mathrm{NTP}$, TFs were significantly decreased compared with the untreated control. The reactive species (ROS or RNS) induced by $\mathrm{N}_{2}$-NTP were quite different from those induced by air-NTP, indicating that nitrogen reactive species from $\mathrm{N}_{2}$-NTP enhanced the activation of bioactive compounds in the djulis seed and that the reactive species from air-NTP inhibited the expression of bioactive compounds in the djulis seed. Human macrophage-differentiated cells (THP-1 cells) may 
be activated for free radicals scavenging and inactivation of ROS or RNS generation in cells treated with djulis seed extract.

Supplementary Materials: The following are available online at https://www.mdpi.com/article/ 10.3390/atmos12111375/s1, Figure S1: The standard of polyphenolic acids and flavonoids. Figure S2. FTIR spectrum on the surface of the air-NTP-treated djulis seed at the condition of Method C (plasma nozzle: A50; Distance: $5 \mathrm{~mm}$, Plasma gas: $\mathrm{N}_{2}$, Power input: $0.8 \mathrm{~kW}$, Sweep speed: $150 \mathrm{~mm} / \mathrm{s}$, Temperature: $46^{\circ} \mathrm{C}$, Torch diameter: $42 \mathrm{~mm}$, Treatment time: $0.68 \mathrm{sec}$ ). Figure S3: The surface of the djulis seed was analyzed using SEM. The surface of the djulis seed without NTP treatment (control) was observed using SEM: SEM 50X (A) and SEM 200X (B). The surface of the djulis seed treated with air-NTP (power input: $800 \mathrm{~W}$, distance: $10 \mathrm{~mm}$, and sweep speed: $100 \mathrm{~mm} / \mathrm{s}$ ) with different plasma nozzles (A50/A30/A10) shown as SEM images: control (C), A50 (D), A30 (E), A10 (F). Figure S4: The distribution of the djulis seed extract without the NTP treatment. Figure S5: The distribution of djulis seed extract with the air-NTP treatment. Figure S6: The distribution of the djulis seed extract with the $\mathrm{N}_{2}$-NTP treatment. Figure S7: The effects of (A) djulis and (B) SWCNT-COOH on THP- 1 cell viability after 24 and $48 \mathrm{~h}$ of exposure. Figure S8: The effects of SWCNT-COOH on THP-1 cell ROS generation after $6 \mathrm{~h}$ of exposure. Figure S9: Effects of pretreatment with djulis seed extract overnight on SWCNT-COOH-induced THP-1 cell ROS generation after $6 \mathrm{~h}$ of exposure.

Author Contributions: Conceptualization, H.-R.C., J.-H.L., W.N.W.M. and Y.-C.L.; data curation, H.R.C. and J.-H.L.; formal analysis, T.-C.L., H.-R.C., C.-H.T., J.-H.L. and M.-H.T.; investigation, J.-H.L., C.-T.C., H.H., I.-C.L., R.D.A. and W.-H.C.; methodology, B.-J.L. and C.-H.T.; project administration, H.-R.C., C.-H.T., J.-H.L., W.N.W.M. and Y.-C.L.; resources, B.-J.L., T.-C.L., H.-R.C., C.-H.T., M.-H.T., R.D.A., W.-H.C., H.-L.C., W.N.W.M. and Y.-C.L.; supervision, H.-R.C., J.-H.L., W.N.W.M. and Y.-C.L.; writing—original draft, B.-J.L., H.-R.C., C.-H.T. and J.-H.L.; writing—review and editing, H.-R.C. and J.-H.L. All authors have read and agreed to the published version of the manuscript.

Funding: The participation of Prof. Ying-Chieh Lee in this study was supported in part by the Higher Education Sprout Project at National Pingtung University of Science and Technology (NPUST 109011).

Data Availability Statement: The data presented in this study are available on request from the corresponding author.

Acknowledgments: The authors wish to thank Meng-Yung Sun at the Department of Chemical and Materials Engineering, National Kaohsiung University of Science and Technology, for assistance with the Non-Thermal Atmospheric Pressure Plasma operation. The authors also wish to thank Chu-Chen Hsueh and En-Tzu Lin in the Institute of Food Safety Management, as well as the Department of Environmental Science and Engineering, National Pingtung University of Science and Technology, for assistance with the djulis analysis. We also acknowledge the assistance of Wei-Tong Liao at the Department of Chemical and Materials Engineering, Southern Taiwan University of Science and Technology, Taiwan, with the responses to the reviewers' comments.

Conflicts of Interest: The authors declare no conflict of interest, including financial interests and personal relationships.

\section{References}

1. Yan, D.; Sherman, J.H.; Keidar, M. Cold atmospheric plasma, a novel promising anti-cancer treatment modality. Oncotarget 2017, 8, 15977. [CrossRef]

2. Hsu, B.; Lin, S.; Inbaraj, B.S.; Chen, B. Simultaneous determination of phenolic acids and flavonoids in Chenopodium formosanum Koidz(djulis) by HPLC-DAD-ESI-MS/MS. Am. Ind. Hyg. Assoc. J. 2017, 132, 109-116. [CrossRef]

3. Perni, S.; Shama, G.; Kong, M.G. Cold atmospheric plasma disinfection of cut fruit surfaces contaminated with migrating microorganisms. J. Food Prot. 2008, 71, 1619-1625. [CrossRef] [PubMed]

4. Laroussi, M.; Akan, T. Arc-free atmospheric pressure cold plasma jets: A review. Plasma Process. Polym. 2007, 4, 777-788. [CrossRef]

5. Lis, K.A.; Kehrenberg, C.; Boulaaba, A.; von Köckritz-Blickwede, M.; Binder, S.; Li, Y.; Zimmermann, J.L.; Pfeifer, Y.; Ahlfeld, B. Inactivation of multidrug-resistant pathogens and Yersinia enterocolitica with cold atmospheric-pressure plasma on stainless-steel surfaces. Int. J. Antimicrob. Agents 2018, 52, 811-818. [CrossRef] [PubMed]

6. Limsopatham, K.; Boonyawan, D.; Umongno, C.; Sukontason, K.L.; Chaiwong, T.; Leksomboon, R.; Sukontason, K. Effect of cold argon plasma on eggs of the blow fly, Lucilia cuprina (Diptera: Calliphoridae). Acta Trop. 2017, 176, 173-178. [CrossRef] [PubMed] 
7. Volkov, A.G.; Hairston, J.S.; Patel, D.; Gott, R.P.; Xu, K.G. Cold plasma poration and corrugation of pumpkin seed coats. Bioelectrochemistry 2019, 128, 175-185. [CrossRef] [PubMed]

8. de Groot, G.J.; Hundt, A.; Murphy, A.B.; Bange, M.P.; Mai-Prochnow, A. Cold plasma treatment for cotton seed germination improvement. Sci. Rep. 2018, 8, 1-10. [CrossRef]

9. Tamošiūnè, I.; Gelvonauskienè, D.; Haimi, P.; Mildažienè, V.; Koga, K.; Shiratani, M.; Baniulis, D. Cold plasma treatment of sunflower seeds modulates plant-associated microbiome and stimulates root and lateral organ growth. Front. Plant Sci. 2020, 11, 1347. [CrossRef] [PubMed]

10. Adhikari, B.; Adhikari, M.; Ghimire, B.; Park, G.; Choi, E.H. Cold atmospheric plasma-activated water irrigation induces defense hormone and gene expression in tomato seedlings. Sci. Rep. 2019, 9, 1-15. [CrossRef]

11. Zhou, R.; Zhou, R.; Zhang, X.; Zhuang, J.; Yang, S.; Bazaka, K.; Ostrikov, K.K. Effects of atmospheric-pressure N 2, He, air, and O 2 microplasmas on mung bean seed germination and seedling growth. Sci. Rep. 2016, 6, 1-11. [CrossRef]

12. Švubová, R.; Slováková, L'.; Holubová, L'.; Rovňanová, D.; Gálová, E.; Tomeková, J. Evaluation of the Impact of Cold Atmospheric Pressure Plasma on Soybean Seed Germination. Plants 2021, 10, 177. [CrossRef] [PubMed]

13. Gómez-Ramírez, A.; López-Santos, C.; Cantos, M.; García, J.L.; Molina, R.; Cotrino, J.; Espinós, J.; González-Elipe, A.R. Surface chemistry and germination improvement of Quinoa seeds subjected to plasma activation. Sci. Rep. 2017, 7, 1-12. [CrossRef] [PubMed]

14. Yodpitak, S.; Mahatheeranont, S.; Boonyawan, D.; Sookwong, P.; Roytrakul, S.; Norkaew, O. Cold plasma treatment to improve germination and enhance the bioactive phytochemical content of germinated brown rice. Food Chem. 2019, 289, 328-339. [CrossRef] [PubMed]

15. Huang, C.-Y.; Chu, Y.-L.; Sridhar, K.; Tsai, P.-J. Analysis and determination of phytosterols and triterpenes in different inbred lines of Djulis (Chenopodium formosanum Koidz.) hull: A potential source of novel bioactive ingredients. Food Chem. 2019, 297, 124948. [CrossRef] [PubMed]

16. Tsai, P.-J.; Hsiao, S.-M.; Chaung, H.-C.; Hong, C.-Z.; Wang, C. The LDL cholesterol-lowering effects of nanoparticled Djulis Grains. ICBBB 2011, 26, 218-221.

17. Hong, Y.-H.; Huang, Y.-L.; Liu, Y.-C.; Tsai, P.-J. Djulis (Chenopodium formosanum Koidz.) water extract and its bioactive components ameliorate dermal damage in UVB-irradiated skin models. Biomed. Res. Int. 2016, 2016. [CrossRef]

18. Tsai, P.-J.; Sheu, C.-H.; Wu, P.-H.; Sun, Y.-F. Thermal and pH stability of betacyanin pigment of djulis (Chenopodium formosanum) in Taiwan and their relation to antioxidant activity. J. Agric. Food Chem. 2010, 58, 1020-1025. [CrossRef] [PubMed]

19. Tsai, P.-J.; Chen, Y.-S.; Sheu, C.-H.; Chen, C.-Y. Effect of nanogrinding on the pigment and bioactivity of djulis (Chenopodium formosanum Koidz.). J. Agric. Food Chem. 2011, 59, 1814-1820. [CrossRef]

20. Lin, T.-A.; Ke, B.-J.; Cheng, C.-S.; Wang, J.-J.; Wei, B.-L.; Lee, C.-L. Red quinoa bran extracts protects against carbon tetrachlorideinduced liver injury and fibrosis in mice via activation of antioxidative enzyme systems and blocking TGF- $\beta 1$ pathway. Nutrients 2019, 11, 395. [CrossRef]

21. Chu, C.-C.; Chen, S.-Y.; Chyau, C.-C.; Fu, Z.-H.; Liu, C.-C.; Duh, P.-D. Protective effect of Djulis (Chenopodium formosanum) and its bioactive compounds against carbon tetrachloride-induced liver injury, in vivo. J. Funct. Foods 2016, 26, 585-597. [CrossRef]

22. Lee, C.-W.; Chen, H.-J.; Chien, Y.-H.; Hsia, S.-M.; Chen, J.-H.; Shih, C.-K. Synbiotic combination of Djulis (Chenopodium formosanum) and Lactobacillus acidophilus inhibits colon carcinogenesis in rats. Nutrients 2020, 12, 103. [CrossRef]

23. Lee, C.-W.; Chen, H.-J.; Xie, G.-R.; Shih, C.-K. Djulis (Chenopodium formosanum) prevents colon carcinogenesis via regulating antioxidative and apoptotic pathways in rats. Nutrients 2019, 11, 2168. [CrossRef]

24. Mancinelli, A.; Yang, L.P.; Lidquist, P.; Anderson, R.; Rabino, I. Photocontrol of anthocyanin synthesis III. The action of streptomycin on the synthesis of chlorophyll and anthocyanin. Plant. Physiol. 1975, 55, 251-257. [CrossRef] [PubMed]

25. Kujala, T.S.; Loponen, J.M.; Klika, K.D.; Pihlaja, K. Phenolics and betacyanins in red beetroot (Beta v ulgaris) root: Distribution and effect of cold storage on the content of total phenolics and three individual compounds. J. Agric. Food Chem. 2000, 48, 5338-5342. [CrossRef]

26. Zhishen, J.; Mengcheng, T.; Jianming, W. The determination of flavonoid contents in mulberry and their scavenging effects on superoxide radicals. Food Chem. 1999, 64, 555-559. [CrossRef]

27. Jin, Z.-Q.; Chen, X. A simple reproducible model of free radical-injured isolated heart induced by 1, 1-diphenyl-2-picryl-hydrazyl (DPPH). J. Pharm. Toxicol Methods 1998, 39, 63-70. [CrossRef]

28. Klas, M.; Ptasinska, S. Characteristics of $\mathrm{N}_{2}$ and $\mathrm{N}_{2} / \mathrm{O}_{2}$ atmospheric pressure glow discharges. Plasma Sources Sci. Technol. 2013, 22, 025013. [CrossRef]

29. Han, X.; Klas, M.; Liu, Y.; Sharon Stack, M.; Ptasinska, S. DNA damage in oral cancer cells induced by nitrogen atmospheric pressure plasma jets. Appl. Phys. Lett. 2013, 102, 233703. [CrossRef]

30. Braný, D.; Dvorská, D.; Halašová, E.; Škovierová, H. Cold atmospheric plasma: A powerful tool for modern medicine. Int. J. Mol. Sci. 2020, 21, 2932. [CrossRef]

31. Thirumdas, R.; Kothakota, A.; Annapure, U.; Siliveru, K.; Blundell, R.; Gatt, R.; Valdramidis, V.P. Plasma activated water (PAW): Chemistry, physico-chemical properties, applications in food and agriculture. Trends Food Sci. Technol. 2018, 77, 21-31. [CrossRef]

32. Mohammadi, E.; Zeinali, M.; Mohammadi-Sardoo, M.; Iranpour, M.; Behnam, B.; Mandegary, A. The effects of functionalization of carbon nanotubes on toxicological parameters in mice. Hum. Exp. Toxicol. 2020, 39, 1147-1167. [CrossRef] 
33. Öner, D.; Moisse, M.; Ghosh, M.; Duca, R.C.; Poels, K.; Luyts, K.; Putzeys, E.; Cokic, S.M.; Van Landuyt, K.; Vanoirbeek, J. Epigenetic effects of carbon nanotubes in human monocytic cells. Mutagenesis 2017, 32, 181-191. [CrossRef] [PubMed]

34. Bhattacharya, K.; Kiliç, G.; Costa, P.M.; Fadeel, B. Cytotoxicity screening and cytokine profiling of nineteen nanomaterials enables hazard ranking and grouping based on inflammogenic potential. Nanotoxicology 2017, 11, 809-826. 